\title{
Stimulation-Produced Spinal Inhibition from the Midbrain in the Rat Is Mediated by an Excitatory Amino Acid Neurotransmitter in the Medial Medulla
}

\author{
L. D. Aimone and G. F. Gebhart \\ Department of Pharmacology, College of Medicine, University of lowa, \\ lowa City, lowa 52242
}

\begin{abstract}
It has been previously established that a bulbar relay plays an important role in descending inhibition of spinal dorsal horn nociceptive neurons and nociceptive reflexes produced by stimulation in the midbrain periaqueductal gray (PAG). In the present study, selected receptor antagonists were microinjected into the medial medullary nucleus raphe magnus (NRM) to determine whether descending inhibition of the tail flick (TF) reflex in the rat produced by focal electrical stimulation in the midbrain PAG was mediated by serotonin, opioid, or glutamate receptors on bulbospinal neurons in the NRM.
\end{abstract}

It was determined in initial experiments that the serotonin receptor antagonist methysergide, the opioid receptor antagonist naloxone, the local anesthetic lidocaine, and the glutamate receptor antagonists $\gamma$-D-glutamylglycine (DGG) and DL-2-amino-5-phosphonovalerate (APV) microinjected into the medulla all significantly increased the threshold of focal electrical stimulation in the medulla required to inhibit the TF reflex. The antinociceptive efficacy of agonists at opioid, serotonin, and glutamate receptors was also tested in other experiments. The microinjection of morphine (2.5-10 $\mu \mathrm{g})$ into the NRM increased significantly TF latencies in a dose-dependent manner in rats in the awake or lightly anesthetized state; morphine was more potent in awake rats. Inhibition of the TF reflex produced by the microinjection of morphine was reversed by a subsequent microinjection of naloxone into the same site in the medulla. The microinjection of serotonin (5 and $10 \mu \mathrm{g}$ ), however, did not affect the latency of the TF reflex in either awake or lightly anesthetized rats. Glutamate $(100 \mathrm{mM}, 0.5 \mu \mathrm{l})$ microinjected into the rostral ventral medulla produced an inhibition of the TF reflex of short duration that could be blocked or attenuated significantly by the glutamate receptor antagonists DGG or APV microinjected into the same site.

In subsequent experiments, a nonspecific functional block was introduced adjacent to the NRM bilaterally in the medullary reticular formations (MRFs) by the microinjection of the local anesthetic lidocaine; receptor antagonists were then microinjected into the NRM and their effect on the threshold of focal electrical stimulation in the PAG to inhibit the TF reflex determined. No increase was seen in stimulation thresholds in the PAG following the microinjection of either methysergide or naloxone into the NRM. Following the microinjection of lidocaine, DGG or APV into the NRM, the stimulation threshold in the PAG for inhibition of the TF reflex was increased significantly.

Received Sept. 4, 1985; revised Nov. 12, 1985; accepted Nov. 21, 1985.

We gratefully acknowledge the excellent secretarial assistance of Marilynn Kirkpatrick and Elizabeth McDonald. Naloxone was graciously supplied by DuPont Pharmaceuticals. This work was supported by USPHS Awards DA 02879 and NS 19912. L.D.A. is supported by T32 GM 07069.

Correspondence should be addressed to L. D. Aimone at the above address.

Copyright $\odot 1986$ Society for Neuroscience 0270-6474/86/061803-1 $1 \$ 02.00 / 0$
These results suggest that glutamate or aspartate, but not serotonin or an endogenous opioid, is a transmitter at the bulbar relay mediating descending inhibition produced by focal electrical stimulation in the midbrain PAG.

The organization in the brain stem of descending systems of spinal inhibition has been the focus of many investigations. Focal electric stimulation in the midbrain periaqueductal gray (PAG), as well as the medullary nucleus raphe magnus (NRM), has been shown to produce an antinociception-i.e., stimulation-produced antinociception, or SPA (Besson et al., 1981; Mayer and Price, 1976; and citations in Sandkühler and Gebhart, 1984a) - and to also inhibit the noxious-evoked excitation of spinal dorsal horn neurons (Gebhart, 1986; Willis, 1982). Similarly, the microinjection of morphine into the PAG or NRM is antinociceptive (Gebhart, 1982; Yaksh and Rudy, 1978) and inhibits spinal dorsal horn nociceptive neurons (Bennett and Mayer, 1979; Clark et al., 1983; Du et al., 1984; Gebhart et al., 1984). Since there are few direct spinopetal efferents from the PAG (Ruda, 1976; see, however, Mantyh and Peschanski, 1982), a bulbar relay, proposed initially to be the NRM (Basbaum and Fields, 1978; Fields and Basbaum, 1978), is interposed between the midbrain PAG and the spinal cord.

While physiological and anatomical studies suggest that the NRM serves as a bulbar relay between the PAG and spinal cord, recent evidence supports the involvement of the laterally adjacent medullary reticular formation (MRF) as well. In the cat, electrolytic lesions of the NRM (Morton et al., 1984) or lidocaine blockade of the NRM (Gebhart et al., 1983b) failed to affect the spontaneous or noxious heat-evoked activity of spinal dorsal horn nociceptive neurons. Only when both the NRM and MRF were simultaneously blocked by the local anesthetic lidocaine was the PAG-produced inhibition of noxious heat-evoked spinal neuronal excitation affected (Gebhart et al., 1983b). In a recent study in the lightly pentobarbital-anesthetized rat, the MRF was also shown to serve as an important bulbar rclay between the midbrain and the spinal cord (Sandkühler and Gebhart, 1984b). Not until the NRM and both adjacent MRFs were simultaneously blocked by lidocaine was the descending inhibition of the nociceptive tail flick (TF) reflex produced by electrical stimulation in the PAG affected (Sandkühler and Gebhart, 1984b). Anatomically, Beitz et al. (1983a) have shown that projections to the NRM and MRF arise from separate but adjacent neurons in the PAG of the rat. It had been previously thought that PAG efferents to the NRM sent collaterals to the MRF (Basbaum and Fields, 1978; Fields and Basbaum, 1978). These studies suggest that excitation of the PAG may activate multiple, perhaps independent, systems of descending inhibition.

The neurotransmitter(s) in the medulla mediating PAG-produced descending inhibition has not been determined. Midbrain efferents to the rostral ventral medulla in the rat have been 
demonstrated to contain enkephalin, serotonin, glutamate, and substance P (e.g., Beitz, 1982; Beitz et al., 1983b; Wiklund et al., 1985; Yezierski et al., 1982). Electrophysiological studies examining the transmitter in the NRM mediating PAG-produced effects have failed to establish roles for norepinephrine (Behbehani et al., 1981; Willcockson et al., 1982), serotonin (Willcockson et al., 1982), or substance P (Pomeroy and Behbehani, 1980). In the present study, pharmacologic antagonists of serotonin, opioid, and glutamate/aspartate receptors were administered into the medial medullary NRM to block presumptive postsynaptic receptors on bulbospinal neurons mediating descending inhibition of the TF reflex produced by focal electrical stimulation in the PAG. Parts of these data have been presented in abstract form (Dilts and Gebhart, 1984).

\section{Materials and Methods}

\section{Animals}

Adult male Sprague-Dawley albino rats (Sasco Inc., Oregon, WI) weighing $250-350 \mathrm{gm}$ on the day of surgery were used in all experiments. Rats were initially anesthetized with $45 \mathrm{mg} / \mathrm{kg}$ pentobarbital sodium (Nembutal) given intraperitoneally. The femoral vein and artery were cannulated and a craniotomy was performed. Following surgery, wound margins were covered with a local anesthetic ointment and a light level of anesthesia (corneal and flexion reflexes present) was maintained thereafter by an intravenous infusion of pentobarbital, 3-6 mg $/ \mathrm{kg} / \mathrm{hr}$ (Gebhart and Ossipov, 1986; Jones and Gebhart, 1986; Sandkühler and Gebhart, 1984a). Rats were warmed on a heating pad; body temperature (rectal probe) and arterial blood pressure were monitored continuously.

Guide cannulae of 26 gauge $(0.46 \mathrm{~mm}$ OD) stainless steel tubing were stereotaxically placed in the PAG, NRM, and bilaterally adjacent MRFs to allow both focal electrical stimulation and drug microinjection at the same intracerebral sites. The incisor bar was set at $3.3 \mathrm{~mm}$ below the horizontal zero (Paxinos and Watson, 1982). Coordinates for placement of cannulae in the PAG were $6.5-6.8 \mathrm{~mm}$ caudal from the bregma and $0.5 \mathrm{~mm}$ lateral to the midline. Coordinates for the NRM were 10.5 $11.0 \mathrm{~mm}$ caudal from the bregma (on the midline); guide cannulae in the MRF were in the same coronal plane as the NRM and were positioned bilaterally $1.1 \mathrm{~mm}$ lateral to the cannula in the NRM and at the identical depth. In all cases, guide cannulae were lowered to $2 \mathrm{~mm}$ above the intended site. [See Sandkühler and Gebhart (1984b) for a full account of the placement of camulae.]

In other animals, a single guide cannula was permanently implanted to a depth $2 \mathrm{~mm}$ above an intended site in the NRM for repeated testing of drug-produced effects in the same animal. These guide cannulae $(0.46$ mm OD; Plastic Products, Roanoke, VA) were permanently affixed to the skull using jeweler's screws and dental acrylic. Experiments were performed on the day of surgery while the rats were lightly anesthetized and also later in the awake state. Drug administration and testing were always separated by at least $2 \mathrm{~d}$.

\section{Noxious stimulation}

The nociceptive TF reflex was evoked by focused radiant heat $(4 \times 10$ $\mathrm{mm}$ area) applied to the underside of the tail (D'Amour and Smith, 1941). Heat was applied randomly to 6-7 evenly spaced sites along the tail starting $2.5 \mathrm{~cm}$ from its distal end. A cut-off time of $7 \mathrm{sec}$ was used to minimize damage to the skin of the tail. Following inhibition of the TF reflex by supraspinal focal electrical stimulation, a control TF always followed at the next interval. Noxious heat was applied at 2 min intervals; this paradigm produced stable baseline TF latencies for several hours without damage to the tail (e.g., Gebhart and Ossipov, 1986; Jones and Gebhart, 1986; Sandkühler and Gebhart, 1984a, b).

\section{Brain stimulation}

Focal electrical brain stimulation of continuous $100 \mathrm{~Hz}$ constant-current, $100 \mu \mathrm{sec}$ duration cathodal pulses was used throughout. Brain stimulation was started $10 \mathrm{sec}$ before and continued during noxious heating of the tail until the TF was evoked or $7 \mathrm{sec}$ elapsed. This paradigm of stimulation has been determined experimentally to require the lowest intensities of stimulation in the PAG for inhibition of the TF reflex (Sandkühler and Gebhart, 1984a). Monopolar stimulating electrodes of 34 gauge ( 0.15 mm OD) insulated magnet wire (tough- pitch copper wire; Belden, Geneva, IL) inserted through the 26 gauge guide cannulae were used throughout. The electrodes were cut to extend $2 \mathrm{~mm}$ beyond the tip of the guide cannulae. Stimulation intensities were increased until the TF reflex was inhibited or non-antinociceptive effects were noted (increases in blood pressure or muscle flexion/extension). Stimulation intensities did not exceed $200 \mu \mathrm{A}$ to minimize spread of current (Ranck, 1975).

\section{Intracerebral microinjections}

Microinjections $(0.5 \mu \mathrm{l})$ were made with 33 gauge $(0.20 \mathrm{~mm}$ OD) injection cannulae inserted into and extending $2 \mathrm{~mm}$ beyond the end of the guide cannulae. The injection was delivered over a $1 \mathrm{~min}$ period, and the injection cannula was left in place for an additional $1 \mathrm{~min}$ to minimize spread of the injectate along the injection track. The progress of the microinjection was continuously monitored by observing the travel of an air bubble in a length of calibrated polyethylene 10 tubing inserted between the injection cannula and a $5 \mu \mathrm{l}$ syringe.

The following drugs and doses (as base) were microinjected into medullary sites: artificial CSF, normal saline, 4\% lidocaine (Astra ${ }^{\circledR}$ ), naloxone $\mathrm{HCl}(1,5,10$, and $20 \mu \mathrm{g})$, methysergide maleate $(5 \mu \mathrm{g})$, morphine $\mathrm{SO}_{4}(2.5,5$, and $10 \mu \mathrm{g}$ ), 5-hydroxytryptamine bimaleate (serotonin; 5 and $10 \mu \mathrm{g}), \gamma$-D-glutamylglycine (DGG; 1 and $5 \mu \mathrm{g}$ ), DL-2-amino-5phosphonovalerate (APV; 1 and $5 \mu \mathrm{g}$ ), and monosodium L-glutamate $(100 \mathrm{~mm})$.

\section{Experimental groups}

Initial experiments were done to establish the efficacy of opioid, serotonergic, and glutaminergic receptor antagonists microinjected in the medulla. After stimulation thresholds for inhibition of the TF reflex were determined to be stable-i.e., 3 consecutive inhibitions of the TF reflex at the same threshold intensity of brain stimulation, each followed by a control TF (see Gebhart and Ossipov, 1986; Jones and Gebhart, 1986; Sandkühler and Gebhart, 1984b)-microinjection of a receptor antagonist was made at the site of stimulation and its effect on the stimulation threshold (at that site) required to inhibit the TF reflex was determined.

In another group of animals, morphine, serotonin, or normal saline was microinjected into the medulla to assess the antinociceptive efficacy of these receptor agonists. The effect of these drugs on the TF reflex latency was determined at 5,15 , and 30 min after intramedullary administration. Experiments were performed in animals while lightly anesthetized and in the same animals later in the awake state.

A third set of experiments was done to determine the efficacy of opioid and glutaminergic receptor antagonists against morphine and glutamate, respectively. Either morphine or glutamate was microinjected into the medulla in separate experiments, its effect on the TF reflex determined, and a receptor antagonist then microinjected into the same site in the medulla. The ability of the antagonist to reverse the effect of the agonist or to block the effects of agonists subsequently microinjected at the same site was determined.

A final series of experiments was done to determine whether a serotonin, glutamate/aspartate, or an opioid receptor in the NRM mediates inhibition of the TF reflex produced by electrical stimulation in the PAG. Stable thresholds of stimulation for inhibition of the TF reflex were established for all 4 sites of stimulation: PAG, NRM, and both MRFs (see above). To produce a nonspecific functional block, lidocaine (4\%) was microinjected into the MRFs bilaterally, and stimulation thresholds in the PAG and NRM were redetermined. The NRM was then selectively blocked by microinjection of either methysergide, naloxone, DGG, or APV. While a functional block was present in the MRFs and the stimulation threshold in the NRM for inhibition of the TF reflex was experimentally established to be increased significantly by the pharmacological antagonist, the stimulation threshold in the PAG for inhibition of the TF reflex was redetermined. In all cases, the effects of lidocaine and the pharmacologic antagonists microinjected into the medulla were time-limited and reversible. This was established by following the return of stimulation thresholds for inhibition of the TF reflex to pre-microinjection intensities of stimulation.

\section{Histology}

At the end of the cxpcriment, rats werc sacrificed with an overdose of pentobarbital. Anodal electrolytical lesions ( $500 \mu \mathrm{A} \mathrm{DC}, 3 \mathrm{sec}$ ) were made to allow for histological verification of stimulation and injection sites in cresyl violet-stained coronal brain sections $(40 \mu \mathrm{m})$. 

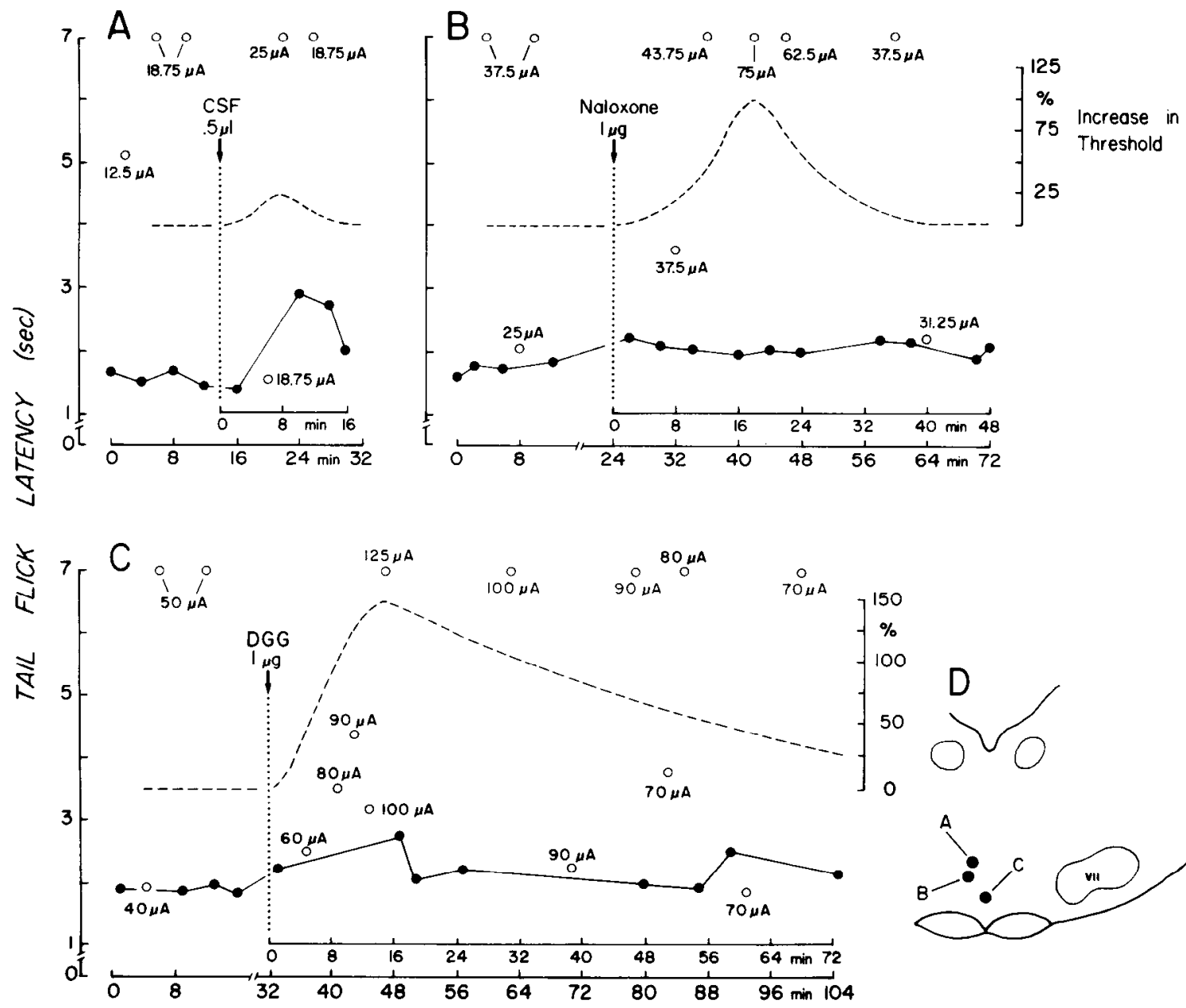

Figure 1. Examples of the effects of the intramedullary administration of CSF $(A)$, naloxone $(B)$, and DGG $(C)$ on stimulation intensities at the site of microinjection for inhibition of the TF reflex. The TF latency (sec) is plotted against time (min); the times of microinjection and doses of antagonists are indicated. Stimulation intensities for inhibition of the TF reflex (TF latency $\geq 7$ sec) are given (open circles); TF latencies in the absence of stimulation are indicated by filled symbols and connected by a solid line. The broken line represents the change (\% increase) in the threshold of stimulation in the medulla required to inhibit the TF reflex (right ordinate). $A$, CSF $(0.5 \mu 1)$ produced a slight, but insignificant, effect on the stimulation threshold in the medulla required to inhibit the TF reflex. $B$, Naloxone $(1 \mu \mathrm{g}$ in $0.5 \mu \mathrm{l})$ increased the medullary stimulation threshold $100 \%$. C, DGG $(1 \mu \mathrm{g}$ in $0.5 \mu \mathrm{l})$ increased the medullary stimulation threshold $150 \%$. $D$, Sites of stimulation/microinjection.

\section{Statistical analyses}

Statistical comparisons were made using Student's paired $t$ test, twoway analysis of variance, and Newman-Keuls test for multiple comparisons; $p \leq 0.05$ was considered significant. Data are presented as means \pm SEM.

\section{Results}

Before testing the effect of receptor antagonists microinjected into the NRM and, by inference, identifying a neurotransmitter at that bulbar relay mediating PAG-produced descending in-

Table 1. Effect of agents microinjected into the medulla on stimulation thresholds at the site of microinjection for inhibition of the nociceptive TF reflex

\begin{tabular}{|c|c|c|c|c|c|c|}
\hline \multirow[b]{2}{*}{ Agent } & \multirow[b]{2}{*}{ Dose $^{a}$} & \multirow[b]{2}{*}{$n$} & \multicolumn{2}{|c|}{ TF inhibitory threshold $(\mu \mathrm{A})$} & \multirow{2}{*}{$\begin{array}{l}\text { Increase in } \\
\text { threshold (\%) }\end{array}$} & \multirow{2}{*}{$\begin{array}{l}\text { Mean duration } \\
\text { of drug effect } \\
\text { (min) }\end{array}$} \\
\hline & & & Predrug & Postdrug & & \\
\hline CSF & $0.5 \mu 1$ & 6 & $27.1 \pm 2.1$ & $29.2 \pm 3.1$ & $6.7 \pm 4.2$ & - \\
\hline Lidocaine & $4 \%$ & 12 & $20.3 \pm 1.7$ & $\geq 3 \times$ predrug* & $\geq 200$ & $32.7 \pm 1.5$ \\
\hline Na!oxone & $1 \mu \mathrm{g}$ & 12 & $26.0 \pm 3.3$ & $53.0 \pm 7.5^{*}$ & $102.9 \pm 10.7$ & $40.0 \pm 5.2$ \\
\hline Methysergide & $5 \mu \mathrm{g}$ & 18 & $26.7 \pm 2.4$ & $\geq 3 \times$ predrug* & $\geq 200$ & $73.9 \pm 4.2$ \\
\hline DGG & $1 \mu \mathrm{g}$ & 14 & $40.4 \pm 4.3$ & $84.6 \pm 9.8^{*}$ & $115.9 \pm 18.7$ & $67.5 \pm 8.1$ \\
\hline APV & $5 \mu \mathrm{g}$ & 7 & $47.1 \pm 4.2$ & $98.6 \pm 12.4^{*}$ & $112.4 \pm 25.2$ & $30.3 \pm 3.4$ \\
\hline
\end{tabular}

Data are reported as means \pm SEM. Asterisks denote significant difference from respective predrug threshold, $p \leq 0.05$ (Student's paired $t$ test).

${ }^{a}$ All intramedullary microinjections were made in a volume of $0.5 \mu \mathrm{l}$. 


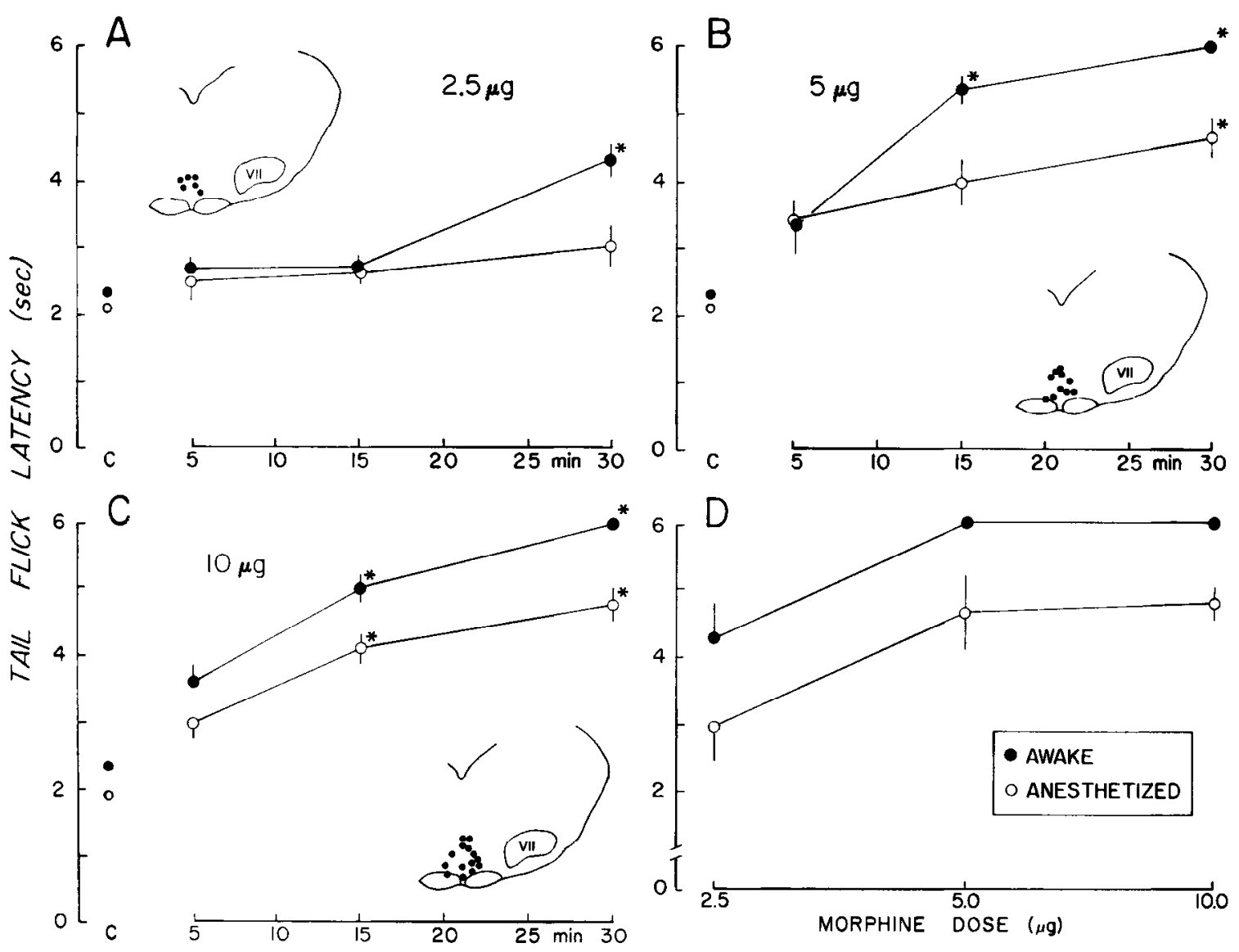

Figure 2. Effects of morphine $(2.5,5$, or $10 \mu \mathrm{g}$ in $0.5 \mu \mathrm{l})$ microinjected into the rostral ventral medulla on the TF latency. The data are presented as means \pm SEM. The open circles represent data from rats in the lightly anesthetized state; data from the same rats in the awake state are represented by filled circles. The pretreatment control TF latencies are indicated by $C$ on the abscissa. $A-C$, TF latency (sec) plotted against time (min) after morphine microinjection. Insets represent sites of morphine microinjection. $D$, Data at 30 min from $A-C$ are summarized; TF latency (sec) is plotted against the dose of morphine. Asterisk indicates a significant difference from the respective pretreatment control TF latency.

hibition, it was first necessary to characterize the efficacy of appropriate receptor agonists as well as the antagonists microinjected into the medulla. Thus, agonists and antagonists at opioid, serotonin, substance $\mathbf{P}$, and glutamate/aspartate receptors were microinjected into the medulla and their antinociceptive efficacy, interaction, and effect on focal electrical stimulation in the medulla were examined in initial experiments.

\section{Efficacy of receptor antagonists and agonists microinjected into the medulla}

In the first series of experiments, the effects of artificial CSF, methysergide, naloxone, lidocaine, and the glutamate/aspartate antagonists, DGG and APV, were examined on stimulation thresholds in the medial medulla for inhibition of the TF reflex.

Methysergide, naloxone, lidocaine, DGG, and APV microinjected into the medulla all significantly increased the stimulation threshold in the medulla for inhibition of the TF reflex (Table 1). Artificial CSF microinjected into the medulla in the same volume $(0.5 \mu 1)$, however, produced a brief, insignificant increase in the stimulation threshold for inhibition of the TF reflex (Fig. 1). The mean increases in stimulation threshold ranged from an approximate doubling in threshold (103\%) for naloxone to $\geq 200 \%$ (lidocaine or methysergide). The effects of the antagonists were time-limited and reversible; the mean durations of increase in stimulation threshold ranged between $30 \mathrm{~min}$ (APV) and 74 min (methysergide). (See also Fig. 1 for examples.)

A variety of substance $P$ antagonists (D-Pro ${ }^{2}, D-P^{2} e^{7}, D-T^{2}{ }^{9}-$ substance $\mathrm{P}, \mathrm{D}-\mathrm{Arg}^{1}, \mathrm{D}-\mathrm{PrO}^{2}, \mathrm{D}-\mathrm{Trp}^{7,9}$, Leu $^{11}$-substance $\mathrm{P}$, and $\mathrm{D}$ -
Pro $^{2}, \mathrm{D}-\mathrm{Trp}^{7,9}$-substance $\mathrm{P} ; 2.5$ and $5 \mu \mathrm{g}$ ) were also microinjected into the NRM. In all cases $(n=8)$, the administration of these agents caused the death of the animal within 13-21 min (respiratory failure and cardiovascular collapse). Thus, the role of substance $P$ as a transmitter candidate in the medulla mediating PAG-produced descending inhibition could not be evaluated.

In a second series of experiments, morphine or serotonin was microinjected into the medulla in rats while lightly anesthetized and again $2 \mathrm{~d}$ later into the same sites in the same rats while awake. Some animals were subsequently reanesthetized and tested again; in all animals testing was separated by $2 \mathrm{~d}$. The sensitivity of the microinjection site was always confirmed by a final microinjection of $10 \mu \mathrm{g}$ of morphine into the NRM in the awake state. This dose of morphine was found to be consistent in producing inhibition of the TF reflex if the site of microinjection was undamaged by previous microinjections. The microinjection of morphine into the NRM in doses of $2.5,5$, or $10 \mu \mathrm{g}$ significantly increased TF latencies in a dose-dependent manner in the same animals in both the lightly anesthetized and awakc states (Fig. 2). Morphine was more potent, however, in awake rats; the antinociception produced by all 3 doses of morphine in awake rats was greater than that produced in the same rats while lightly anesthetized (Fig. $2 D$ ).

The microinjection of serotonin into the NRM at doses of 5 or $10 \mu \mathrm{g}$ did not affect the latency of the TF reflex at any time tested in either the awake or anesthetized state (Fig. 3). Similarily, at no time following its microinjection did normal saline affect the latency of the TF reflex in either awake or anesthetized 


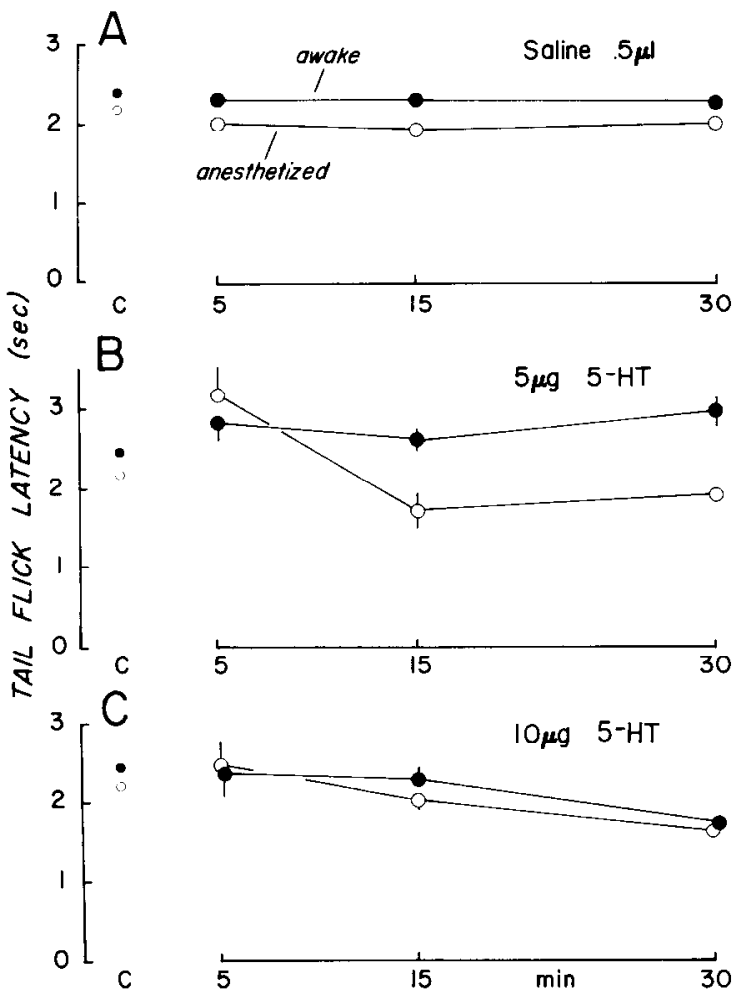

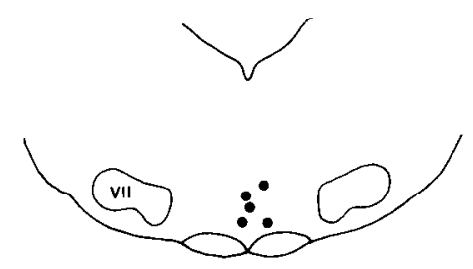
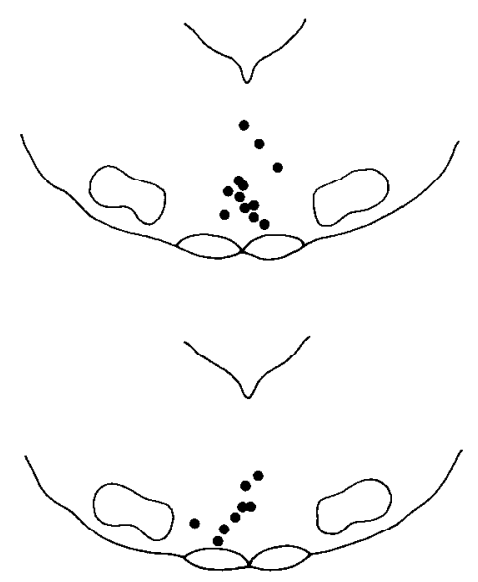

Figure 3. Effects of saline $(0.5 \mu \mathrm{l})$ or serotonin (5-HT; 5 and $10 \mu \mathrm{g}$ in 0.5 $\mu l)$ microinjected into the rostral ventral medulla on the TF latency. Data are presented as means \pm SEM. The TF latency (sec) is plotted against time (min) after microinjection. The pretreatment control TF latencies are indicated by $C$ on the abscissa. Filled circles represent data from rats in the awake state; data from the same rats while lightly anesthetized are represented by open circles. The sites of microinjection are represented at the right. rats. It should be noted that the control TF latency while lightly anesthetized was significantly shorter than the TF latency in the same rats when tested while awake. The mean TF latencies of the 35 pairs of rats described in Figures 2 and 3 were $2.10 \pm$ 0.06 and $2.38 \pm 0.05 \mathrm{sec}$, respectively, for lightly anesthetized and awake animals $(t=3.0547 ; p<0.005)$. This confirms earlier results from this laboratory (Sandkühler and Gebhart, 1984a) suggesting that light pentobarbital anesthesia releases the TF reflex from tonic descending inhibition, resulting in a relative hyperalgesia.

Glutamate $(100 \mathrm{~mm}, 0.5 \mu \mathrm{l})$ microinjected into the ventral medulla produced an inhibition of the TF reflex. The duration of this inhibition was $5.06 \pm 1.55 \mathrm{~min}$, after which the TF reflex latencies returned to control (Fig. 4A). Sites in the medulla at which inhibition of the TF reflex produced by glutamate was blocked or attenuated by the putative glutamate receptor antagonists APV or DGG are shown in Figure $4 B$ as an example. In 9 experiments, glutamate was microinjected into the medulla, producing inhibition of the TF reflex. After TF reflex latencies had returned to control, APV $(5 \mu \mathrm{g})$ or DGG $(1 \mu \mathrm{g})$ was microinjected into the same site in the medulla followed by a second microinjection of glutamate into the same site. In 9/9 instances, the effects of glutamate were blocked or attenuated significantly by the prior administration of either APV or DGG (see example in Fig. 4B). To assure that microinjection of glutamate did not render the injection site insensitive to subsequent microinjections of glutamate, thus suggesting an efficacy for DGG or APV that neither possesses, glutamate microinjections were made twice into the same site in a different group of rats. In $5 / 5$ cases, glutamate produced inhibition of the TF reflex following a second microinjection (see example in Fig. $4 A$ ), the duration of which was equal to that of inhibition produced by the initial microinjection of glutamate (these 5 sites are also shown in Fig. 4B).

In Figure $4 C$, sites at which the microinjection of morphine $(10 \mu \mathrm{g})$ into the medulla produced an inhibition of the TF reflex that was subsequently reversed by the microinjection of nalox- one $(10$ or $20 \mu \mathrm{g})$ at the same site are shown; an example is also given. In all cases in which morphine produced an inhibition of the TF reflex, the subsequent microinjection of naloxone reversed morphine's effect and returned the TF reflex latencies to control values.

\section{$P A G$ stimulation and medullary blockade}

The foregoing experiments establish that opioid and glutamate receptors in the NRM, when acted on by an appropriate agonist, produce a pharmacologically reversible inhibition of the TF reflex (i.c., an antinociception). In the final set of experiments, the effects of the opioid receptor antagonist naloxone, the serotonin receptor antagonist methysergide, and the glutamate receptor antagonists DGG and APV microinjected into the NRM were tested for their efficacy against stimulation-produced inhibition of the TF reflex from the PAG. Stable stimulation thresholds for inhibition of the TF reflex were established in the PAG, NRM, and bilaterally in the MRFs. Lidocaine was then microinjected into the MRFs bilaterally at 2 sites per side $1 \mathrm{~mm}$ apart dorsoventrally to produce a complete functional block of laterally descending pathways. The spread of lidocainc $(4 \%, 0.5 \mu l)$ and the duration of its effect when employed in this fashion have been previously determined (Sandkühler and Gebhart, 1984b). After the microinjections of lidocaine, stimulation thresholds for inhibition of the TF reflex in the PAG and NRM were experimentally established as unchanged. A selected receptor antagonist or lidocaine was then microinjected into the NRM at 2 sites $1 \mathrm{~mm}$ apart dorsoventrally. While all medullary sites of microinjection/stimulation were blocked by lidocaine (MRFs) and lidocaine or a receptor antagonist (NRM), the stimulation threshold in the PAG for inhibition of the TF reflex was determined, following which the stimulation thresholds for inhibition of the TF reflex from all 3 sites in the medulla were redetermined. Only experiments in which stimulation thresholds at all 3 sites in the brain stem could be experimentally tested following drug microinjection were included in the data analysis. It was determined in the first series of experiments 
Figure 4. Examples of the effects of the intramedullary administration of glutamate, DGG, and morphine and naloxone on TF reflex latencies. The TF reflex latency (sec) is plotted against time (min); the times of administration and doses of antagonists are indicated. TF latencies are indicated by filled symbols and are connected by a solid line. Inhibition of the TF reflex is represented by a TF reflex latency of $7 \mathrm{sec}$. $A$, Microinjection of glutamate $(100 \mathrm{~mm}, 0.5 \mu \mathrm{l})$ into the NRM (indicated at right) produces an inhibition of the TF reflex of short duration; the effect is reproducible. To the right of $A$, the sites of microinjection of glutamate $(100 \mathrm{~mm}, 0.5 \mu \mathrm{l})$ producing inhibition of the TF reflex are represented by the filled circles; open circles represent sites at which the microinjection of glutamate was without effect on TF latencies. $B$, Inhibition of the TF reflex by glutamate $(100 \mathrm{~mm}, 0.5 \mu \mathrm{l})$ is prevented by pretreatment with DGG $(1.0 \mu \mathrm{g}$ in $0.5 \mu \mathrm{l})$ microinjected into the same site in the NRM (indicated at right). To the right of $B$, the sites of microinjection of APV $(5 \mu \mathrm{g}$ in $0.5 \mu \mathrm{l})$ or DGG $(1 \mu \mathrm{g}$ in 0.5 $\mu \mathrm{l})$, which blocked or significantly attenuated a subsequent microinjection of glutamate $(100 \mathrm{~mm}, 0.5 \mu \mathrm{l})$, are represented by filled circles. The filled triangles represent sites at which the microinjection of glutamate $(100 \mathrm{~mm}$, $0.5 \mu$ l) inhibited the TF reflex twice in succession when microinjected into the same site. $C$. Inhibition of the TF reflex by morphine $(10 \mu \mathrm{g}$ in $0.5 \mu \mathrm{l})$ is reversed by the subscquent microinjection of naloxone $(20 \mu \mathrm{g}$ in 0.5 $\mu$ ) into the same site in the NRM (indicated at right). To the right of $C$, sites of microinjection of naloxone (10 or $20 \mu \mathrm{g}$ in $0.5 \mu \mathrm{l}$ ), which reversed the inhibition of the TF reflex produced by the prior microinjection of morphine $(10 \mu \mathrm{g}$ in $0.5 \mu \mathrm{l})$ into the same site. The sites of microinjection for the examples given are indicated in histological reconstructions to the right.
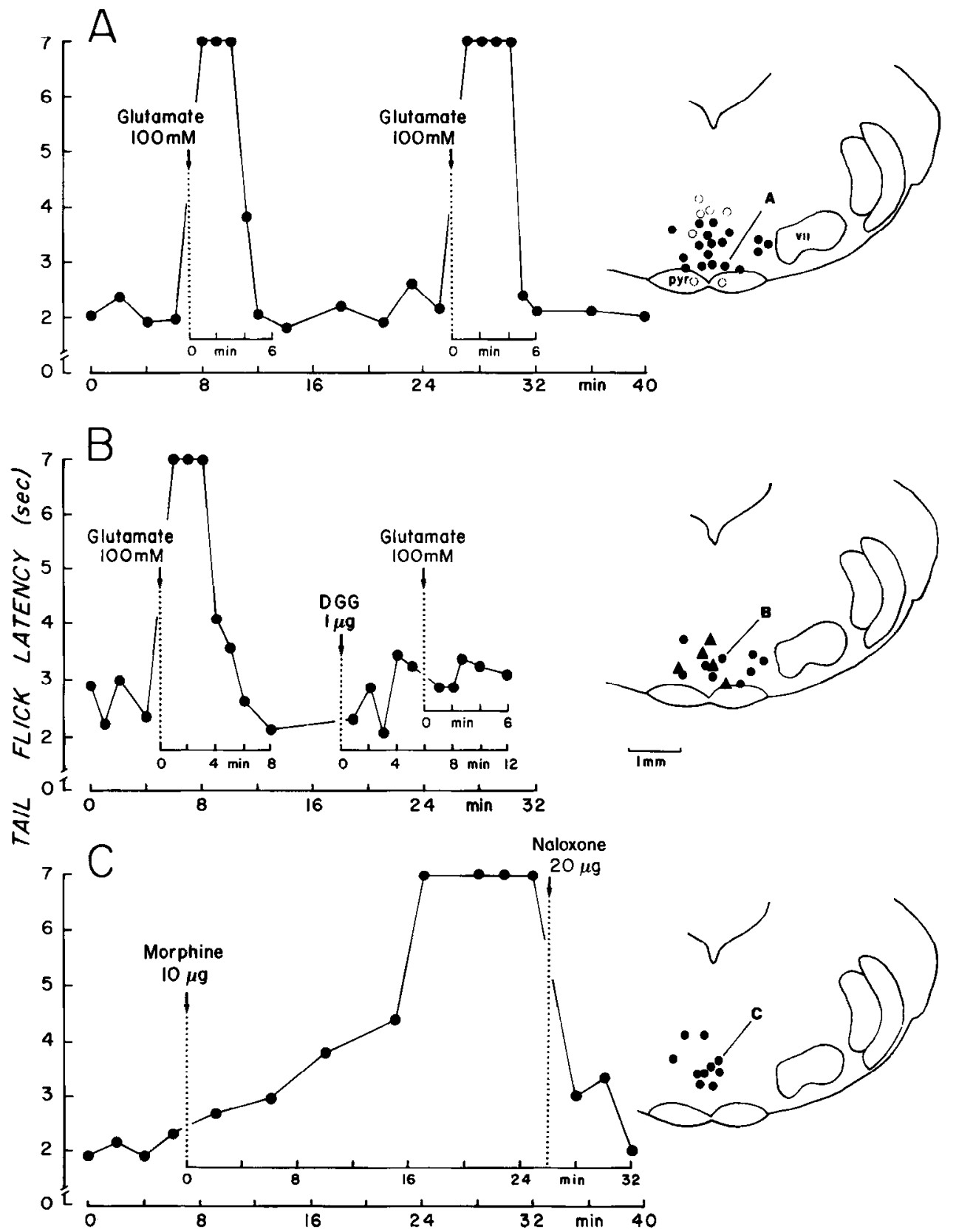

(Table 1) that the microinjection of lidocaine or the selected receptor antagonists produced a significant increase in stimulation thresholds; therefore, experiments in which significant increases in stimulation thresholds in the medulla were not produced were also not included in the data analysis $(n=4)$.

The data from these experiments are summarized in Table 2 and Figure 5. When the rostral ventral medullary NRM and MRFs bilaterally were blocked simultaneously with lidocaine, the stimulation threshold in the PAG for inhibition of the TF reflex increased significantly: $143.2 \pm 18.2 \%$ (Fig. $5 \mathrm{~A}$ ). Microinjection of methysergide or naloxone into the NRM when the MRFs bilaterally were blocked simultaneously with lidocaine failed to affect the intensity of stimulation in the PAG required to inhibit the TF reflex: $5.0 \pm 5.0 \%$ and $9.0 \pm 5.5 \%$ increases in threshold, respectively (Fig. $5, B, C$ ). Microinjection of the putative nonselective glutamate/aspartate antagonist (Sawada and Yamamoto, 1984) DGG into the NRM when the MRFs were simultaneously blocked bilaterally with lidocaine signifi- cantly increased the stimulation threshold in the PAG required to inhibit the TF reflex: $70.1 \pm 12.1 \%$ (Fig. $5 E$ ). The putative selective $N$-methyl-D-aspartate (NMDA) antagonist (Foster and Fagg, 1984) APV was employed to confirm the effects produced by DGG; APV also increased significantly the stimulation threshold in the PAG: $82.1 \pm 6.9 \%$ (Fig. $5 D$ ). In 2 experiments, lidocaine and DGG were both microinjected dorsal to the MRFs and NRM, respectively. These microinjections caused significant increases in stimulation thresholds at the medullary sites of microinjection, but the PAG stimulation threshold for inhibition of the TF reflex remained unchanged (Fig. $5 F$ ), thus confirming the specificity of the site of effect. In 4 additional experiments, DGG and APV were microinjected into 2 sites 1 $\mathrm{mm}$ apart dorsoventrally in the NRM as described above, but the adjacent MRFs were not blocked by lidocaine. The stimulation threshold in the PAG for inhibition of the TF reflex was unchanged in these experiments: $55.0 \pm 5.0 \mu \mathrm{A}$ vs $57.5+4.8$ $\mu \mathrm{A}$ before and after microinjection in the NRM, respectively. 


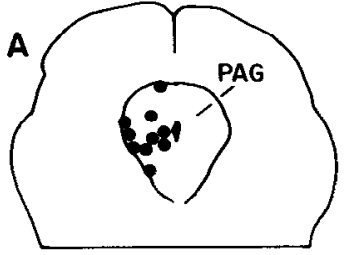

$143.2 * 18.2 \%$
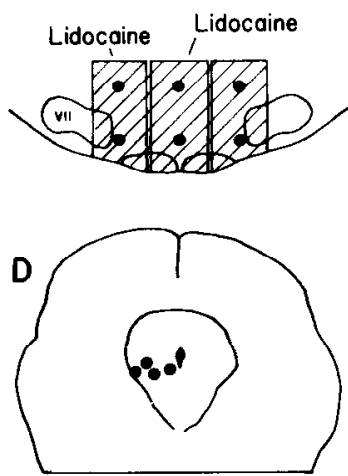

$82.1 \neq 6.9 \%$

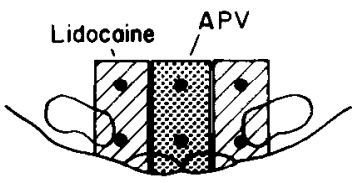

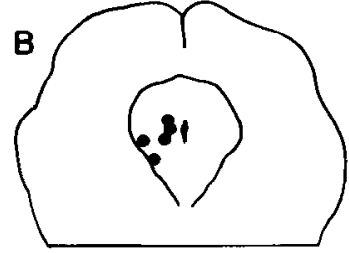

$5.0 \pm 5.0 \%$
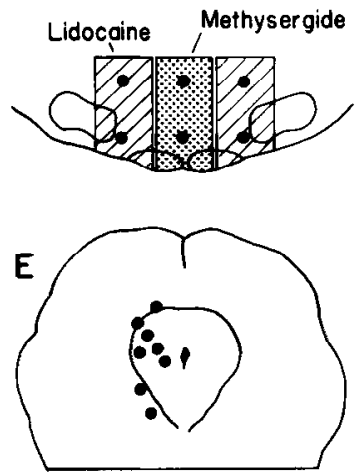

$71.1 * 12.1 \%$

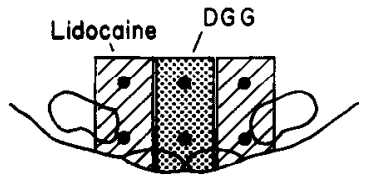

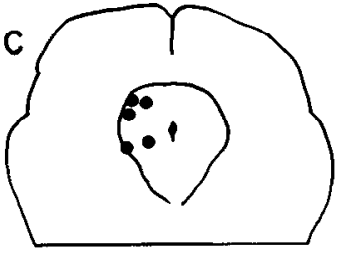

$9.0 * 5.5 \%$
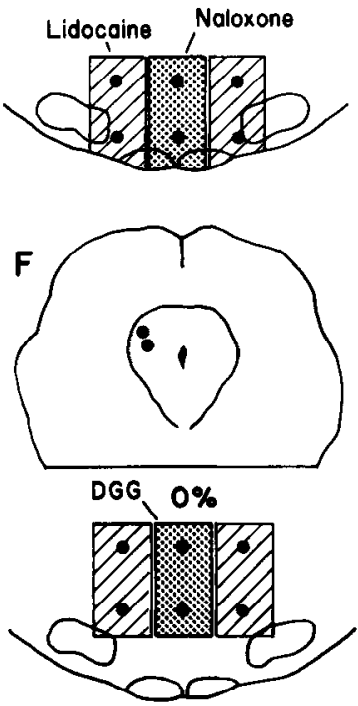

Figure 5. Effects of the intramedullary microinjection of lidocaine or receptor antagonists on stimulation thresholds in the midbrain PAG for inhibition of the TF reflex. $A-F$, Sites (filled circles) of stimulation in the midbrain (above) and of microinjection in the medulla (below). The estimated area of functional block produced by lidocaine microinjected in the medulla is indicated by the crosshatched areas. The estimated block produced by the antagonist is represented by the stippled areas. The mean percentage increase \pm SEM of the midbrain stimulation threshold for inhibition of the TF reflex produced by medullary microinjections is indicated for each set of experiments. See text for additional details.
That the stimulation threshold in the NRM was increased significantly while the PAG threshold remained unchanged argues against a nonspecific action of the glutamate antagonists at the bulbar relay between the PAG and spinal cord.

\section{Discusslon}

These results implicate an excitatory amino acid as a transmitter in the medial rostral ventral medulla mediating descending inhibition produced by focal electrical stimulation in the midbrain PAG. Strengthening this conclusion is evidence that two different putative glutamate receptor antagonists, DGG and APV, were efficacious in this regard, while microinjections of DGG and lidocaine dorsal in the medulla, or microinjections of DGG or APV into the NRM in the absence of lidocaine block of the MRFs, did not affect the TF inhibitory stimulation threshold in the PAG. In addition to the site specificity demonstrated, receptor selectivity of the effects observed is supported by the failure of either naloxone or methysergide to affect the PAG stimulation threshold for inhibition of the TF reflex. It was also confirmed in these studies that agonist interaction at opioid or glutamate receptors in the medulla activates descending inhibition of the TF reflex.

Electrophysiological investigations have established that stimulation in the PAG evokes a short-latency response in neurons in the NRM (Fields and Anderson, 1978; Mason et al., 1985; Pomeroy and Behbehani, 1979; Vanegas et al., 1984; Willcockson et al., 1982). Vanegas et al. (1984) recently reported that $85 \%$ of 31 neurons in the rostral ventromedial medulla increased activity during PAG stimulation at intensities sufficient to inhibit the TF reflex. Behbehani and Fields (1979) re-

Table 2. Effects of agents microinjected into the medial medulla on stimulation thresholds in the midbrain PAG for inhibition of the nociceptive TF reflex

\begin{tabular}{|c|c|c|c|c|c|}
\hline \multirow[b]{2}{*}{ Agent } & \multirow[b]{2}{*}{ Dose $^{a}$} & \multirow[b]{2}{*}{$n$} & \multicolumn{2}{|c|}{ TF inhibitory threshold $(\mu \mathrm{A})$} & \multirow{2}{*}{$\begin{array}{l}\text { Increase in } \\
\text { threshold } \\
(\%)\end{array}$} \\
\hline & & & Predrug & Postdrug & \\
\hline Lidocaine & $4 \%$ & 10 & $62.0 \pm 6.5$ & $143.0 \pm 10.9^{*}$ & $143.2 \pm 18.2$ \\
\hline Methysergide & $5 \mu \mathrm{g}$ & 5 & $115.0 \pm 17.0$ & $120.0 \pm 16.6$ & $5.0 \pm 5.0$ \\
\hline Naloxone & $1 \mu \mathrm{g}$ & 5 & $75.0 \pm 13.1$ & $77.5 \pm 12.8$ & $9.0 \pm 5.5$ \\
\hline APV $b$ & $5 \mu \mathrm{g}$ & 4 & $70.0 \pm 0.0$ & $127.5 \pm 4.8^{*}$ & $82.1 \pm 6.9$ \\
\hline $\mathrm{DGG}^{b}$ & $1 \mu \mathrm{g}$ & 8 & $74.4 \pm 6.5$ & $123.8 \pm 10.5^{*}$ & $70.1 \pm 12.1$ \\
\hline DGG (dorsal sites) & $1 \mu \mathrm{g}$ & 2 & $90.0 \pm 10.0$ & $90.0 \pm 10.0$ & $0.0 \pm 0.0$ \\
\hline
\end{tabular}

The medullary reticular formation bilaterally was blocked simultaneously with lidocaine (see text for additional information) Data are reported as means \pm SEM. Asterisks denote significant difference from respective predrug threshold, $p \leq 0.05$ (Student's paired $t$ test).

a All intramedullary microinjections were given in two sites, $1 \mathrm{~mm}$ apart dorsoventrally, in volumes of $0.5 \mu 1$ each (see Fig. 5).

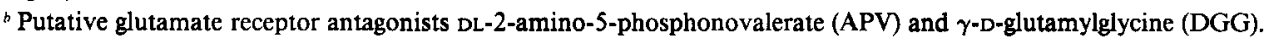


ported earlier that excitation of cells in the PAG by the microinjection of glutamate is correlated with an increased firing of cells in the NRM and is also associated with elevation of a flexion reflex threshold. They concluded that an excitatory connection between the PAG and NRM, when activated, produces an antinociception. More recently, Mason et al. (1985) reported that sites of electrical stimulation in the PAG that suppress the jaw-opening reflex evoke monosynaptic postsynaptic potentials in pontomedullary neurons, thus supporting the hypothesis that stimulation-produced effects from the PAG are mediated, at least in part, through the direct activation of neurons in the NRM. The foregoing establishes electrophysiologically the excitatory connection from the PAG to the NRM; anatomical evidence also has been provided recently. By mapping amino acid afferents to the NRM autoradiographically, Wiklund et al. (1985) identified a connection between the PAG and NRM in which glutamate/aspartate serves as the neurotransmitter. This anatomical evidence further supports the present results that descending inhibition produced by focal electrical stimulation in the PAG is mediated by glutamate/aspartate released in the NRM.

Establishing a role for glutamate as an excitatory neurotransmitter in the CNS has been hampered by its presence as an intermediate in neuronal metabolism. Biochemical and electrophysiological investigations, however, have satisfied many of the criteria for establishment of glutamate as a neurotransmitter (Fonnum, 1984; Johnson, 1978; Watkins and Evans, 1981). Precursors for its synthesis and metabolizing enzymes have been demonstrated in the CNS (Hamberger et al., 1979a, b). Glutamate also is taken up into synaptic vesicles in a $\mathrm{Na}^{+}$-dependent manner, and on depolarization its release is $\mathrm{Ca}^{2+}$-dependent (Fonnum, 1984). Studies employing lesion techniques further support a role for glutamate as a transmitter in the hippocampus, olfactory bulb, cerebellum, and other areas (Watkins and Evans, 1981). Saturable and reversible binding sites for glutamate also have been found to be unevenly distributed throughout the brain; binding is most prominent in hippocampus and cortex, areas reflecting putative glutaminergic pathways (Greenamyre et al., 1984). This binding has a $K_{\mathrm{d}}$ in the high nanomolar range with a $B_{\max }$ of approximately $15 \mathrm{pmol} / \mathrm{mg}$ protein (Fagg and Matus, 1984; Greenamyre et al., 1984). The varying potency and efficacy of a variety of glutamate agonists have led to the proposal that there exist multiple excitatory amino acid receptor subtypes (see Foster and Fagg, 1984; and Watkins and Evans, 1981, for review). Unfortunately, an antagonist able to distinguish between receptor binding by glutamate and aspartate has not been developed. That glutamate or aspartate is the excitatory neurotransmitter linking the PAG and the NRM in the production of descending inhibition has not been previously demonstrated. While present in low levels as compared to the hippocampus, glutamate binding also is seen in the PAG and in the NRM (Greenamyre et al., 1984). The present data indicate that these glutamate binding sites in the NRM may play a functional role in descending inhibition arising from the PAG.

There have been previous investigations of the contribution of medullary structures to descending inhibition from the PAG (e.g., Behbehani and Fields, 1979; Gebhart et al., 1983b; Llewelyn et al., 1984; Mohrland et al., 1982; Morton et al., 1984; Prieto et al., 1983; Sandkühler and Gebhart, 1984b). Most studies have focused on the NRM in the rostral ventral medulla. Behbehani and Fields (1979) reported that lesions in the NRM and an area approximately $500 \mu \mathrm{m}$ in diameter next to this nucleus were effective in blocking the antinociceptive effect of glutamate given in the PAG. Recently, Prieto et al. (1983) reported a high positive correlation between the percentage of NRM destroyed and the percentage increase in the stimulation threshold in the ventral PAG for inhibition of the TF reflex.
While the NRM undeniably plays a role in descending inhibition from the midbrain, the weight of evidence argues against a central, exclusive role for the NRM. Morton et al. (1984) and Gebhart et al. (1983b) have established that inhibition of spinal dorsal horn nociceptive neurons produced by stimulation in the PAG is unaffected by either electrolytic lesions or revisible lidocaine block of the NRM, respectively. It was determined, rather, that both the medial and lateral ventral medulla were important bulbar relays between the PAG and spinal cord (Gebhart et al., 1983b). Later, Sandkühler and Gebhart (1984b) demonstrated that a local anesthetic block of the medial and lateral ventral medulla simultaneously by lidocaine is required to increase significantly the stimulation threshold in the PAG for inhibition of the TF reflex. It was considered in the present study that if relevant receptors in the NRM were blocked selectively by a receptor antagonist while the MRFs were simultaneously nonselectively blocked with lidocaine, the neurotransmitter(s) in the medial medulla, functionally important to descending inhibition produced by stimulation in the midbrain, could be determined. The stimulation threshold in the PAG for inhibition of the TF reflex was increased significantly only following microinjection of lidocaine, DGG, or APV into the NRM; naloxone and methysergide were ineffective.

Conflicting results concerning the role of serotonin as the neurotransmitter in the medial medullary NRM, however, have been reported by Llewelyn et al. (1984). Following the microinjection of methysergide $(5 \mu \mathrm{g})$ into the NRM, they observed a complete block of the antinociception (inhibition of the TF reflex) produced by stimulation in the PAG. However, they observed no change in PAG-produced antinociception following either microinjection of a different serotonin receptor antagonist (cinanserin) or the local ancsthetic tctracaine. It is possible that the large microinjection volume $(2 \mu \mathrm{l})$ employed was sufficient to produce a block of both medial and lateral brain-stem sites. There was apparently no verification of either the efficacy or spread of methysergide or tetracaine, and it is not clear at present why only methysergide, but neither cinanserin nor tetracaine, was found to be efficacious in their experiments (Llewelyn et al., 1984).

Lovick (1985) recently reported that bilateral electrolytic lesions in the rostral ventrolateral medulla abolished both the antinociceptive and cardiovascular effects produced by electrical stimulation in the PAG. These results are concluded to be at variance with the work of Sandkühler and Gebhart (1984b)and also with results repeated here-due to the different general anesthetic used (Saffan) and the longer control TF reflex latencies $(2.5-3.5 \mathrm{sec})$. There is, however, a more significant experimental variable likely contributing to the divergent results. In both the present and earlier study (Sandkühler and Gebhart, 1984b), the intensity of supraspinal stimulation in the PAG required to inhibit the TF reflex was the dependent variable measured. In the study by Lovick (1985), the dependent variable was the measure of antinociceptive and cardiovascular effects produced by a fixed intensity of electrical stimulation in the PAG. The inhibitory intensity of focal electrical stimulation often increases slightly before stabilizing (e.g., Gebhart and Ossipov, 1986; Jones and Gebhart, 1986; Sandkühler and Gebhart, 1984a); thus, the experimental criterion employed here and elsewhere (Gebhart and Ossipov, 1986; Jones and Gebhart, 1986; Sandkühler and Gebhart, 1984a) is that the TF reflex must be inhibited three times consecutively by the same intensity of stimulation (each followed by a control TF in the absence of supraspinal stimulation) before that intensity is identified as the inhibitory threshold. In other experiments where the effects of receptor antagonists administered into the spinal intrathecal space were examined on supraspinal stimulation-produced inhibition of the TF reflex, the intensity of stimulation for inhibition of the TF 
reflex always increased slightly, perhaps due to nonspecific changes produced by drug injection (Gebhart and Ossipov, 1986; Jones and Gebhart, 1986). So too did both naloxone and methysergide in the present study produce slight, insignificant increases in the stimulation threshold in the PAG. Thus, the intensity of stimulation in the PAG has been routinely used as the dependent variable in this laboratory. It is not known in the study of Lovick (1985) whether increasing the intensity of stimulation in the PAG would have overcome the effect of the electrolytic lesions or whether changes in lesion size, local edema, or bleeding, etc., could have contributed to the results. Unfortunately, it is not possible to evaluate functionally the extent of area influenced by electrolytic lesions during the course of an experiment (as one can with a local anesthetic block).

There is a substantial and somewhat confusing literature regarding antagonism by naloxone of stimulation-produced antinociception (SPA) from the PAG. Many investigators have reported that the systemic administration of naloxone significantly attenuates SPA (e.g., Adams, 1976; Akil et al., 1976; Hosobuchi et al., 1977), while others have failed to observe an effect of naloxone (e.g., Gebhart and Toleikis, 1978; Pert and Walter, 1976; Yaksh et al., 1976). Recently, Cannon et al. (1982) reported that naloxone antagonizes SPA from the ventral, but not dorsal, PAG, suggesting that qualitatively different forms of SPA can be evoked from the midbrain and perhaps clarifying some of the confusion in the literature regarding naloxone's efficacy. Neither in the present nor related studies, however, was a difference observed either in inhibitory efficacy or susceptibility to medullary manipulations among electrodes placed dorsoventrally in the PAG (Gebhart et al., 1983a; Morton et al., 1984; Sandkühler and Gebhart, 1984a, b; see, however, Prieto et al., 1983). In this and another study (Llewelyn et al., 1984), the inability of naloxone to increase significantly the stimulation threshold in the PAG for inhibition of the TF reflex indicates that the locus of naloxone's action is not at the level of the bulbar relay between the PAG and the spinal cord. Further, the intrathecal administration of naloxone also is unable to block SPA from the PAG (Aimone et al., 1986). Thus, naloxone's antagonism of SPA from the PAG likely occurs supraspinally. That an endogenous opioid is not the transmitter of the PAGNRM connection also is supported anatomically (Beitz, 1982). Using a combined retrograde HRP immunohistochemical procedure, very few enkephalin (and substance $P$ )-containing fibers from the PAG to the NRM were observed in the rat. In an electrophysiological study by Pomeroy and Behbehani (1980), the iontophoretic application of substance $P$ onto neurons in the NRM was compared to the response of those same neurons to focal stimulation in the PAG. Using this method, they failed to establish a role for substance $P$ in the NRM. In the present study various substance $P$ antagonists were tried, but all produced death on microinjection into the NRM.

Ossipov and Gebhart (1984) reported that light pentobarbital anesthesia in rats shifts the antinociceptive dose-response curve for morphine administered into the PAG to the right. They concluded that it is likely that pentobarbital anesthesia depresses the descending inhibitory pathway(s) activated by morphine administered into the PAG. The present study examined in a similar fashion the effects of light pentobarbital anesthesia on the inhibition of the TF reflex produced by morphine microinjected into the NRM. Morphine was found to be more potent in awake than lightly anesthetized rats, a result similar to that found following the intra-PAG administration of morphine (Ossipov and Gebhart, 1984). While a greater potency was seen in awake rats, the difference in the potency of morphine between the awake and anesthetized states was less dramatic in the present than previous study. It is possible that the depression produced by pentobarbital has less effect on the descending systems influenced by morphine administered into NRM, perhaps because morphine's influence in the NRM activates a single system of descending inhibition while morphine microinjected into the PAG activates multiple systems of descending inhibition.

In contrast to morphine, serotonin was without effect on the TF reflex when microinjected into the NRM in either awake or lightly anesthetized rats. This result conflicts with a report that $5 \mu$ g serotonin microinjected into the NRM inhibited the TF reflex but not a paw-withdrawal reflex (Llewelyn et al., 1983). The result may be related to the large volume of microinjection $(2 \mu 1)$ and production, for example, of a nonspecific mechanical effect. It has been recommended that $0.5 \mu \mathrm{l}$ is the largest volume that should be microinjected intracerebrally into rat brain to limit the influence of distant sites (Myers, 1966). The volume of the microinjection notwithstanding, it is difficult to understand how serotonin microinjected into the NRM could activate a system of descending inhibition. Inhibitory serotonin autoreceptors have been demonstrated on serotonin-containing neurons (Aghajanian and Wang, 1978) in the CNS, an observation consistent with the inhibition, not excitation, of raphe-spinal neurons by serotonin. Wessendorf and Anderson (1983) reported that serotonergic raphe-spinal neurons in the NRM were inhibited ( $83 \%$ of 30 neurons) by the direct iontophoretic application of serotonin. Similarly, Willcockson et al. (1982) reported that both the glutamate-evoked excitation ( 29 of 31 ) and spontaneous activity ( 5 of 6 ) of raphe-spinal neurons were inhibited by the iontophoretic application of serotonin. Further, serotonin iontophoresed onto 12 raphe-spinal neurons inhibited the increase in neuronal activity of 7 cells produced by electrical stimulation in the PAG (Willcockson et al., 1982). Based on these considerations, one would not expect serotonin microinjections into the NRM either to excite raphe-spinal neurons or to produce an antinociception.

Glutamate is generally held to nonselectively excite only cell bodies (Goodchild et al., 1982; Johnson, 1972). Glutamate microinjected into the PAG or NRM will inhibit the TF reflex (Behbehani and Fields, 1979; Jensen and Yaksh, 1984; Satoh et al., 1983; Urca et al., 1980; e.g., see Fig. 4A), but this does not allow one to determine if it is acting selectively at glutamate receptors or nonspecifically exciting cell bodies. That the antagonists DGG and APV were able to block or significantly attenuate the effects of glutamate microinjected into the NRM suggests that glutamate inhibits the TF reflex at least partly through an action at specific glutamate receptors. The putative glutamate/aspartate receptor antagonist DGG has been shown to suppress depolarizations induced by L-aspartate, D-L homocysteate, or L-glutamate (Sawada and Yamamoto, 1984), while APV has been shown to act relatively selectively at the NMDA glutamate receptor (Foster and Fagg, 1984). The use of these receptor antagonists does not allow us to distinguish between the 2 excitatory amino acids glutamate and aspartate. Yet similar results with 2 different glutamate/aspartate antagonists, and the lack of effect of DGG microinjected dorsal to the NRM, support our conclusion that an excitatory amino acid is a transmitter candidate in the medial rostral ventral medulla mediating descending inhibition produced by focal electrical stimulation in the midbrain PAG. DGG and APV increased the stimulation threshold in the PAG somewhat less than did complete block of the NRM with lidocaine (70 and $82 \%$ increase in threshold vs $143 \%$ increase, respectively). This difference may be doserelated, but we found essentially equivalent effects of DGG and APV at doses of 1 and $5 \mu \mathrm{g}$.Thus, it is likely that a neurotransmitter(s) other than either glutamate or aspartate is also involved in the bulbar relay that mediates descending inhibition from the midbrain. Alternatively, direct spinopetal fibers from the PAG may have been unaffected by either DGG or APV but would have been blocked with lidocaine (e.g., see Manthy and 
Peschanski, 1982). Further, since either the medial or lateral ventral medulla can serve as the bulbar relay from the PAG to the spinal cord, the present study addresses only a portion of the descending pathways mediating spinal inhibition from the midbrain. The neurotransmitter in the MRF between the PAG and spinal cord is presently unknown but may well be different than determined for the NRM in the present study, since Beitz et al. (1983a) have established that adjacent, but different, neurons in the PAG send efferents to the NRM and MRF.

\section{References}

Adams, J. E. (1976) Naloxone reversal of analgesia produced by brain stimulation in the human. Pain 2: 161-166.

Aghajanian, G. K., and R. Y. Wang (1978) Physiology and pharmacology of central serotonergic neurons. In Psychopharmacology: $A$ Generation of Progress, M. A. DiMascio and K. F. Killam, eds., pp. 171-183, Raven, New York.

Aimone, L. D., S. L. Jones, and G. F. Gebhart (1986) Spinal neurotransmitters mediating stimulation-produced inhibition of the tail flick reflex from the periaqueductal gray and nucleus raphe magnus. Fed. Proc. 45.

Akil, H., D. J. Mayer, and J. C. Leibeskind (1976) Antagonism of stimulation-produced analgesia by naloxone, a narcotic antagonist. Science 191: 961-962.

Basbaum, A. I., and H. L. Fields (1978) Endogenous pain control mechanisms: Review and hypothesis. Annu. Neurol. 4: 451-462.

Behbehani, M. M., and H. L. Fields (1979) Evidence that an excitatory connection between the periaqueductal gray and the nucleus raphe magnus mediates stimulation produced analgesia. Brain Res. 170: 85-93.

Behbehani, M. M., S. L. Pomeroy, and C. E. Mack (1981) Interaction between central gray and nucleus raphe magnus: Role of norepinephrine. Brain Res. Bull. 6: 361-364.

Beitz, A. J. (1982) The nuclei of origin of brainstem enkephalin and substance $\mathbf{P}$ projections to the rodent nucleus raphe magnus. Neuroscience 7: 2753-2768.

Beitz, A. J., M. A. Mullet, and L. L. Weiner (1983a) The periaqueductal projections to the rat spinal trigeminal, raphe magnus, gigantocellular pars alpha and paragigantocellular nuclei arise from separate neurons. Brain Res. 288: 307-314.

Beitz, A. J., R. D. Shepard, and W. E. Wells (1983b) The periaqueductal gray-raphe magnus projection contains somatostatin, neurotensin and serotonin but not cholecystokinin. Brain Res. 261: 132137.

Bennett, G. J., and D. J. Mayer (1979) Inhibition of spinal cord interneurons by narcotic microinjection and focal electrical stimulation in the periaqueductal central gray matter. Brain Res. 172: 243-257.

Besson, J.-M., J.-L. Oliveras, A. Chaouch, and J.-P. Rivot (1981) Role of the raphe nuclei in stimulation producing analgesia. Adv. Exp. Med. Biol. 133: 153-176.

Cannon, J. T., G. J. Prieto, A. Lee, and J. C. Liebeskind (1982) Evidence for opioid and non-opioid forms of stimulation-produced analgesia in the rat. Brain Res. 243: 315-321.

Clark, S. L., R. O. Edeson, and R. W. Ryall (1983) The relative significance of spinal and supraspinal actions in the antinociceptive effort of morphine in the dorsal horn: An evaluation of the microinjection technique. Br. J. Pharmacol. 79: 307-319.

D'Amour, F. E., and D. L. Smith (1941) A method for determining loss of pain sensation. J. Pharmacol. Exp. Ther. 72: 74-79.

Dilts, L. M., and G. F. Gebhart (1984) Studies on the transmitter in the medulla mediating descending inhibition produced in the midbrain. Soc. Neurosci. Abstr. 10: 107.

Du, H.-J., L.-M. Kitahata, J. G. Thalhammer, and M. Zimmermann (1984) Inhibition of nociceptive neuronal responses in the cat's spinal dorsal horn by electrical stimulation and morphine microinjection in nucleus raphe magnus. Pain 19: 121-130.

Fagg, G. E., and A. Matus (1984) Selective association of n-methylaspartate and quisqualate types of L-glutamate receptors with brain postsynaptic densities. Proc. Natl. Acad. Sci. USA 81: 6876-6880.

Fields, H. L., and S. D. Anderson (1978) Evidence that raphe-spinal neurons mediate opiate and midbrain stimulation-produced analgesia. Pain 5: 333-349.

Fields, H. L., and A. I. Basbaum (1978) Brainstem control of spinal pain-transmission neurons. Annu. Rev. Physiol. 40: 217-248.
Fonnum, F. (1984) Glutamate: A neurotransmitter in mammalian brain. J. Neurochem. 42: 1-11.

Foster, A. C., and G. E. Fagg (1984) Acidic amino acid binding sites in mammalian neuronal membranes: Their characteristics and relationships to synaptic receptors. Brain Res. Rev. 7: 103-164.

Gebhart, G. F. (1982) Opiate and opioid effects on brainstem neurons: Relevance to nociception and antinociceptive mechanisms. Pain 2 : 93-140.

Gebhart, G. F. (1986) Modulatory effects of descending systems on spinal dorsal horn neurons. In Spinal Afferent Processing, T. L. Yaksh, ed., pp. 391-416, Plenum, New York.

Gebhart, G. F., and M. H. Ossipov (1986) Characterization of inhibition of the spinal nociceptive tail-flick reflex in the rat from the medullary lateral reticular nucleus. J. Neurosci. 6: 701-713.

Gebhart, G. F., and J. R. Toleikis (1978) An evaluation of stimulation produced analgesia in the cat. Exp. Neurol. 62: 570-579.

Gebhart, G. F., J. Sandkühler, J. G. Thalhammer, and M. Zimmermann (1983a) Quantitative comparison of inhibition in spinal cord of nociceptive information by stimulation in periaqueductal gray or nucleus raphe magnus of the cat. J. Neurophysiol. 50: 1433-1445.

Gebhart, G. F., J. Sandkühler, J. G. Thalhammer, and M. Zimmermann (1983b) Inhibition of spinal nociceptive information by stimulation in midbrain of the cat is blocked by lidocaine microinjected in nucleus raphe magnus and medullary reticular formation. J. Neurophysiol. 50: $1446-1459$.

Gebhart, G. F., J. Sandkühler, J. G. Thalhammer, and M. Zimmermann (1984) Inhibition in spinal cord of nociceptive information by electrical stimulation and morphine microinjection at identical sites in midbrain of the cat. J. Neurophysiol. 51: 75-89.

Goodchild, H. K., R. A. L. Dampney, and R. Bandler (1982) A method for evoking physiological responses by stimulation of cell bodies, but not axons of passage within localized regions of the central nervous system. J. Neurosci. Methods 6: 351-363.

Greenamyre, J. T., A. B. Young, and J. B. Penney (1984) Quantitative autoradiographic distribution of $\mathrm{L}-\left[{ }^{3} \mathrm{H}\right]$-glutamate-binding sites in the rat central nervous system. J. Neurosci. 4: 2133-2144.

Hamberger, A. C., G. H. Chiang, E. S. Nylen, S. W. Scheff, and C. W. Cotman (1979a) Glutamate as a CNS transmitter. I. Evaluation of glucose and glutamine as precursors for the synthesis of preferentially released glutamate. Brain Res. 168: 513-530.

Hamberger, A., G. H. Chiang, E. Sandoval, and C. W. Cotman (1979b) Glutamate as a CNS transmitter. II. Regulation of synthesis in the releasable pool. Brain Res. 168: 531-541.

Hosobuchi, Y., J. E. Adams, and R. Linchitz (1977) Pain relief by electrical stimulation of the central gray matter in humans and its reversal by naloxone. Science 197: 183-186.

Jensen, T. S., and T. L. Yaksh (1984) Spinal monoamine and opioid systems partially mediate an analgesia produced by glutamate at brainstem sites. Brain Res. 321: 287-298.

Johnson, J. L. (1972) Glutamic acid as a synaptic transmitter in the nervous system: A review. Brain Res. 37: 1-19.

Johnson, J. L. (1978) The excitant amino acids glutamic and aspartic acid as transmitter candidates in the vertebrate nervous system. Prog. Neurobiol. 10: 155-202.

Jones, S. L., and G. F. Gebhart (1986) Characterization of coeruleospinal inhibition of the nociceptive tail-flick reflex in the rat: Mediation by spinal $\alpha_{2}$-adrenoceptors. Brain Res. 36: 315-330.

Llewelyn, M. B., J. Azami, and M. H. T. Roberts (1983) Effects of 5-hydroxy-tryptamine applied into nucleus raphe magnus on nocicepetive thresholds and neuronal firing rate. Brain Res. 258: 59-68.

Llewelyn, M. B., J. Azami, and M. H. T. Roberts (1984) Antinociception produced by stimulation of the periaqueductal gray matter: Effects of antagonists microinjected into the nucleus raphe magnus. Pain (Suppl.) 2: S220.

Lovick, T. A. (1985) Ventrolateral medullary lesions block the antinociceptive and cardiovascular responses elicited by stimulating the dorsal periaqueductal grey matter in rats. Pain 21: 241-252.

Mantyh, P. W., and M. Peschanski (1982) Spinal projections from the periaqueductal gray and dorsal raphe in the rat, cat and monkey. Neuroscience 7: 2769-2776.

Mason, P., A. Strassman, and R. Maciewicz (1985) Pontomedullary raphe neurons: Monosynaptic excitation from midbrain sites that suppress the jaw opening reflex. Brain Res. 329: 384-389.

Mayer, D. J., and D. D. Price (1976) Central nervous system mechanisms of analgesia. Pain 2: 379-404.

Mohrland, J. S., D. Q. McManus, and G. F. Gebhart (1982) Lesions 
in the nucleus reticularis gigantocellularis: Effect on the antinociception produced by microinjection of morphine and focal brain stimulation in the periaqueductal gray matter. Brain Res. 231: 143-152.

Morton, C. R., A. W. Duggan, and Z. Q. Zhao (1984) The effects of lesions of medullary midline and lateral reticular areas on inhibition in the dorsal horn produced by periaqueductal gray stimulation in the cat. Brain Res. 301: 121-130.

Myers, R. D. (1966) Injection of solutions into cerebral tissue: Relation between volume and diffusion. Physiol. Behav. 1: 171-174.

Ossipov, M. H., and G. F. Gebhart (1984) Light pentobarbital anesthesia diminishes the antinociceptive potency of morphine administered intracranially but not intrathecally in the rat. Eur. J. Pharmacol. 97: 137-140.

Paxinos, G., and C. Watson (1982) The Rat Brain in Stereotaxic Coordinates, Academic, New York.

Pert, A., and M. Walter (1976) Comparison between naloxone reversal of morphine and electrical stimulation induced analgesia in the rat mesencephalon. Life Sci. 19: 1023-1032.

Pomeroy, S. L., and M. M. Behbehani (1979) Physiologic evidence for a projection from periaqueductal gray to nucleus raphe magnus in the rat. Brain Res. 176: 143-147.

Pomeroy, S. L., and M. M. Behbehani (1980) Response of nucleus raphe magnus neurons to iontophoretically applied substance $P$ in rats. Brain Res. 202: 464-468.

Prieto, G. J., J. T. Cannon, and J. C. Liebeskind (1983) N. raphe magnus lesions disrupt stimulation-produced analgesia from ventral but not dorsal midbrain areas in the rat. Brain Res. 261: 53-57.

Ranck, J. B., Jr. (1975) Which elements are excited in electrical stimulation of mammalian central nervous system: A review. Brain Res. 98: 417-440.

Ruda, M. A. (1976) Autoradiographic examination of the efferent projections of the midbrain central gray in the cat. Ph.D. thesis, University of Pennsylvania.

Sandkühler, J., and G. F. Gebhart (1984a) Characterization of inhibition of a spinal nociceptive reflex by stimulation medially and laterally in the midbrain and medulla in the pentobarbital-anesthetized rat. Brain Res. 305: 67-76.

Sandkiihler, J., and G. F. Gebhart (1984h) Relative contribution of the nucleus raphe magnus and adjacent medullary reticular formation to the inhibition by stimulation in the periaqueductal gray of a spinal nociceptive reflex in the pentobarbital-anesthetized rat. Brain Res. 305: 77-87.

Satoh, M., R. Oku, and A. Akaike (1983) Analgesia produced by microinjection of $l$-glutamate into the rostral ventromedial bulbar nuclei of the rat and its inhibition by intrathecal $\alpha$-adrenergic blocking agents. Brain Res. 261: 361-364.

Sawada, S., and G. Yamamoto (1984) Gamma-D-glutamylglycine and cis-2,3-piperidine dicarboxylate as antagonists of excitatory amino acids in the hippocampus. Exp. Brain Res. 55: 351-358.

Urca, G., R. L. Hin, and J. C. Liebeskind (1980) Glutamate-induced analgesia: Blockade and potentiation by naloxone. Brain Res. 192. 523-530.

Vanegas, H., N. M. Barbaro, and H. L. Fields (1984) Midbrain stimulation inhibits tail flick only at currents sufficient to excite rostral medullary neurons. Brain Res. 321: 127-133.

Watkins, J. C., and R. H. Evans (1981) Excitatory amino acid transmitters. Annu. Rev. Pharmacol. Toxicol. 21: 165-204.

Wessendorf, M. W., and E. G. Anderson (1983) Single unit studies of identified bulbospinal serotonergic units. Brain Res. 279: 93-103.

Wiklund, L., M. Persson, and M. Cuénod (in press) An autoradiographic attempt to identify amino acid afferents to the rat nucleus raphe magnus by retrograde $\left[{ }^{3} \mathrm{H}\right]$-D-aspartate and $\left[{ }^{125} \mathrm{I}\right]$-wheat germ agglutinin labelling. J. Comp. Neurol.

Willcockson, W. S., K. D. Gerhart, C. I. Cargill, and W. D. Willis (1982) Effects of biogenic amines on raphe spinal tract cells. J. Pharmacol. Exp. Ther. 225: 637-645.

Willis, W. D. (1982) Control of Nociceptive Transmission in the Spinal Cord, Springer-Verlag, Heidelberg.

Yaksh, T. L., and T. A. Rudy (1978) Narcotic analgetics: CNS sites and mechanisms of action as revealed by intracerebral injection lechniques. Pain 4: 299-359.

Yaksh, T. L., J. L. Yeung, and T. A. Rudy (1976) An inability to antagonize with naloxone the elevated nociceptive thresholds resulting from electrical stimulation of the mesencephalic central gray. Life Sci. 18: 1193-1198.

Yezierski, R. P., R. M. Bowker, G. A. Kevetter, J. D. Coulter, and W. D. Willis (1982) Serotonergic projections to the caudal brain stem: A double label study using horseradish peroxidase and serotonin immunocytochemistry. Brain Res. 239: 258-264. 